\title{
Distributed PLL-based Control of Offshore Wind Turbines Connected with Diode-Rectifier based HVDC Systems
}

\author{
Lujie Yu, Rui Li, and Lie Xu, Senior Member, IEEE
}

\begin{abstract}
A distributed PLL-based frequency control is proposed in this paper for offshore wind turbine converters connected with diode-rectifier based high-voltage-direct-current (HVDC) systems. The proposed control enables a large number of wind turbines to work autonomously to contribute to the offshore $\mathrm{AC}$ frequency and voltage regulation. The proposed control also provides automatic synchronization of the offline wind turbines to the offshore AC grid. Stability of the proposed frequency control is analyzed using root locus method. Moreover, an active dc voltage control of the onshore modular multilevel converter (MMC) is proposed to ride-through onshore $\mathrm{AC}$ fault, where the onshore MMC converter quickly increases the dc voltage by adding additional submodules in each phase, in order to rapidly reduce wind farm active power generation so as to achieve quick active power re-balance between the offshore and onshore sides. Thus the overvoltage of the submodule capacitor is alleviated during the onshore fault, reducing the possibility of system disconnection. Simulation results in PSCAD verify the proposed control strategy during start-up, synchronization and under onshore and offshore fault conditions.
\end{abstract}

Index Terms - diode-rectifier based HVDC, distributed PLLbased frequency control, offshore wind power integration, onshore AC fault, synchronization of wind turbine converters

\section{INTRODUCTION}

$\mathrm{I}$ $\mathrm{N}$ Europe, onshore wind farms have already been well developed, and more attention has been drawn to offshore sites. Many large offshore wind farms will be developed in the near future, thus reliable and efficient technology for transmitting the offshore wind power is one of the main development focuses. High voltage direct current (HVDC) technology has been identified as a preferred choice for longdistance offshore wind power transmission [1]-[7].

To date, voltage-source-converter based HVDC (VSCHVDC) links have been successfully used in offshore wind farm connection projects, while line-commutated-converter based HVDC (LCC-HVDC) links are largely used for bulky power transmission in strong onshore ac grids. Recently, connection of offshore wind farm using diode-rectifier based HVDC (DR-HVDC) systems where diode rectifiers are used at

This project has received funding from the European Union's Horizon 2020 research and innovation programme under grant agreement No 691714.

The authors are with the Department of Electronic and Electrical Engineering, University of Strathclyde, Glasgow, G1 1XW UK (e-mail: lujie.yu@ strath.ac.uk, rui.li@strath.ac.uk, lie.xu@strath.ac.uk). the offshore wind farm site and connected to a conventional MMC at onshore has received noticeable interests [8]-[15]. This approach was firstly suggested in [8]-[11], and has been further developed in industry for offshore wind farm connection [12], [13]. The main benefits of DR-HVDC when compared to VSC-HVDC are lower investment and space requirement, higher efficiency and robustness. As reported in [12], [13], compared with VSC-HVDC for wind farm connection, the volume and transmission losses are reduced by $80 \%$ and $20 \%$ respectively, while the total cost can be reduced by $30 \%$.

However, the uncontrolled diode-rectifier is unable to control offshore frequency and voltage as VSC-HVDC systems do. Thus, in DR-HVDC connected offshore wind farms, wind turbine (WT) converters have to control the offshore ac voltage and frequency. In [8], a voltage and frequency control is proposed, while communication for a centralized voltage control is required and all the wind turbines start-up from the beginning, with the synchronization process not being addressed. The fault ride-through performance and the operation with reduced diode rectifier filter are analyzed in [10], [11] using the same control strategy. In [13], umbilical ac cables are used to start-up the unidirectional DR-HVDC and a reactive power frequency droop control is presented. With no inner current loop for the WT converter, the dynamic response of the system during fast transients has yet to be approved. A fixed frequency control suggested in [14] can maintain a stable offshore frequency and can be a potential solution for synchronization, but global positioning system (GPS) is required for each WT. In fact, for the converters used in the power system and industry, phase-locked loop (PLL) is a much simpler and more efficient tool for system synchronization [16], [17].

Therefore, in this paper, a new distributed PLL-based frequency control is proposed for the operation of the WT converters connected with DR-HVDC system. Unlike in [8][11], communication is not required for the proposed distributed PLL-based frequency control. And a major difference of the proposed method in relation to the control method in [14] is that the synchronization tool of the proposed control is based on PLL, which is much simpler and more efficient than GPS used in [14]. In this paper, automatic synchronization of offline wind turbines to the network is studied in detail, which has not been analyzed before. Furthermore, the onshore modular multilevel converter has not been properly studied in all the previous DR-HVDC research 
This paper is a post-print of a paper submitted to and accepted for publication in IEEE Transactions on Power Delivery and is subject to Institution of Electrical and Electronic Engineering Copyright. The copy of record is available at IEEE Xplore Digital Library.

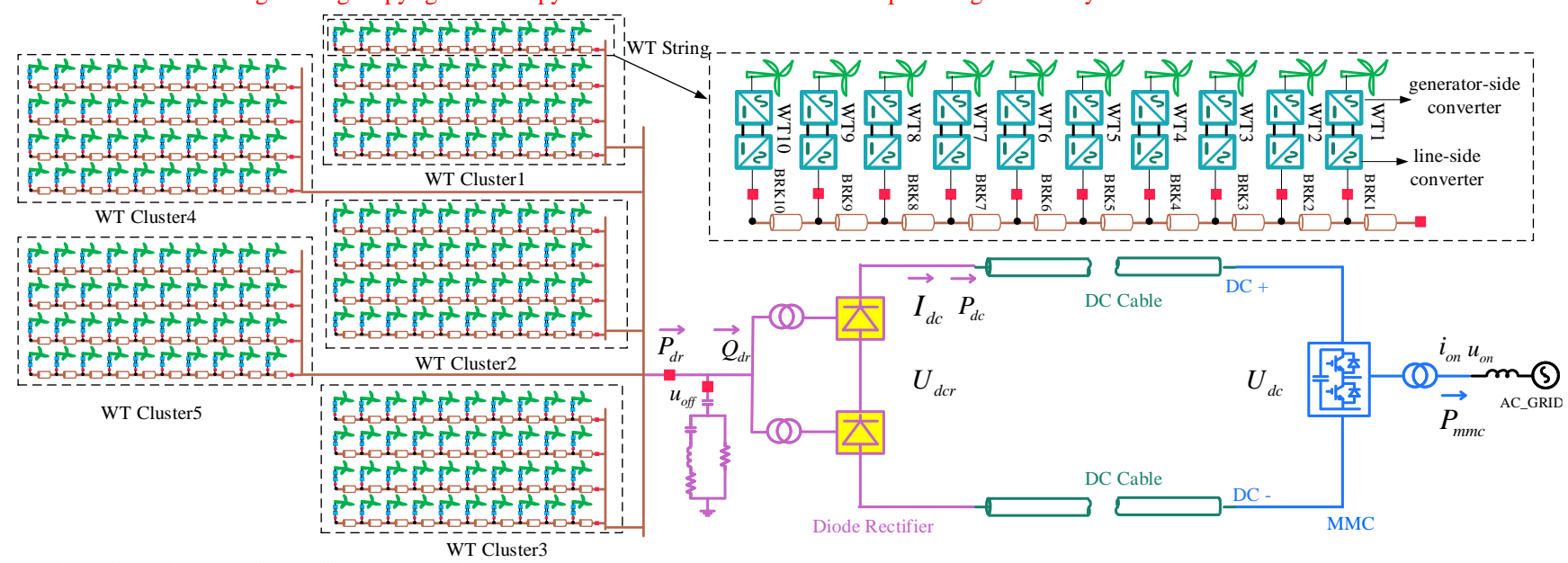

Fig. 1 Single line diagram of the offshore wind farm system connected with DR- HVDC

work, especially the onshore fault ride through performance of the system. This paper proposes an active dc voltage control of the onshore modular multilevel converter (MMC), which can quickly re-balance the active power in the DR-HVDC system during the onshore fault and alleviate the overvoltage of the onshore MMC submodule capacitors during the fault without the use of communication.

The rest of this paper is organized as follows. The DR-HVDC structure and basic control are presented in Section II. In Section III, the proposed distributed PLL-based frequency control is described and its stability is analyzed. The proposed active MMC DC voltage control for onshore ac fault ridethrough operation is presented in Section IV. Simulation results are presented in Section V to validate the proposed control and finally Section VI draws conclusions.

\section{DR-HVDC}

\section{A. Structure}

The considered offshore wind farm connected with DRHVDC is shown in Fig. 1, which consists of five WT clusters. Each cluster is made up of four WT strings with ten fully rated converter based WTs. The diode-rectifier is made up of a 12pulse bridge, whose DC sides are connected in series by two 6pulse bridges while the ac sides are connected in parallel through a star-star and a star-delta connected transformers respectively. The onshore MMC with half-bridge submodules controls the dc voltage of the DR-HVDC link.

\section{B. Basic control of WT line-side converters with DR-HVDC}

\section{1) Control requirements}

When connected with DR-HVDC, the WT line-side converters have to work as grid-forming converters rather than grid-feeding converters. In addition to balancing transmitted active power between WT and offshore network, line-side converters also need to establish the offshore network frequency and voltage [8], [9]. The control requirements of the line-side converters are as follows:

- Offshore ac voltage control. During the start-up and normal operation, the offshore network voltage should be controlled. In addition, over-voltage should be limited during transient conditions, e.g. onshore ac fault.

- Active power control. The line-side converters need to transmit active power based on WT operation requirement, e.g. maximum power point tracking.

- Reactive power sharing control. Reactive power needs to be shared among WT converters while reactive current circulation among them is avoided.

- Frequency control. The line-side converters need to regulate the frequency of offshore network and ensure offline WTs can easily synchronize to the offshore ac grid.

Fig. 2 shows the overall structure of the system control for the WT line-side converters. The detailed functions and designs of the individual control block will be described in the following sections.

\section{2) Inner current control}

The inner current loop has been widely used for controlling VSC with the benefit of fast response and current limiting during external ac faults. For the converter circuit shown in Fig. 2 , the VSC current loop dynamics in the $d q$ reference frame in which the $q$-axis component of the VSC filter bus voltage $\boldsymbol{U}_{\boldsymbol{F}}$ is approximately 0 , are expressed as

$$
\begin{aligned}
& R I_{W d}+L \frac{d I_{W d}}{d t}=U_{C d}-U_{F d}+\omega L I_{W q} \\
& R I_{W q}+L \frac{d I_{W q}}{d t}=U_{C q}-U_{F q}-\omega L I_{W d}
\end{aligned}
$$

where $\omega$ is the angular frequency of the offshore network. With proportional-integral (PI) regulators, the current control loop is illustrated in Fig. 2.

\section{3) Voltage control}

As shown in Fig. 2, the voltage dynamics of the WT line-side converter in the $d q$ reference frame are described as

$$
\begin{aligned}
& C \frac{d U_{F d}}{d t}=I_{W d}-I_{s d}+\omega C U_{F q} \\
& C \frac{d U_{F q}}{d t}=I_{W q}-I_{s q}-\omega C U_{F d}
\end{aligned}
$$

By regulating the output current of the converter, the voltage at the VSC filter capacitor terminal $\boldsymbol{U}_{\boldsymbol{F}}$ can be controlled to follow its reference. The control diagram of the voltage loop 
This paper is a post-print of a paper submitted to and accepted for publication in IEEE Transactions on Power Delivery and is subject to Institution of Electrical and Electronic Engineering Copyright. The copy of record is available at IEEE Xplore Digital Library.

can be seen in Fig. 2. The output $d q$ current limits are set according to the converter current rating.

\section{4) Active power control}

As the dc voltage of the DR-HVDC link is controlled at the rated value by the onshore MMC, the transmitted active power is largely determined by the dc voltage produced by the diode rectifier $\left(U_{d c}\right.$, Fig. 2) [9]. The dc voltage produced by the diode rectifier is given as

$$
U_{d c r}=2\left(1.35 U_{\text {off }}-\frac{3}{\pi} X I_{d c}\right)
$$

where $\mathrm{X}$ is the reactance of the diode rectifier transformer. Thus, the active power transmitted from the wind farm to the onshore HVDC is determined by the offshore ac grid voltage $U_{\text {off }}$ or VSC filter capacitor terminal voltage $\boldsymbol{U}_{\boldsymbol{F}}$. Therefore, a WT active power control loop can be implemented as shown in Fig. 2 whose output is the amplitude of the $d$-axis voltage reference, i.e. magnitude of the produced offshore ac voltage. $U_{o}$ is the ac voltage set point of the offshore WT converters.

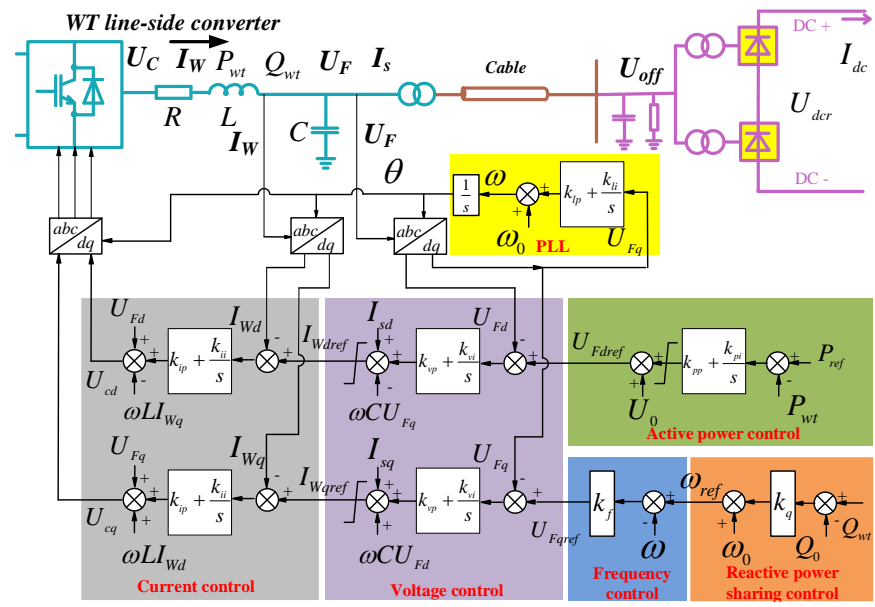

Fig. 2 Diagram of WT line-side converter control

\section{5) Reactive power sharing control}

When a large number of WTs are connected to the diode rectifier, the reactive power needs to be shared among the WTs to avoid over-currents and reactive current circulation. The adopted reactive power sharing control [8], [13] is shown in Fig. 2 where a reactive power frequency droop is used as

$$
\omega_{\text {ref }}=k_{q}\left(Q_{w t}-Q_{0}\right)+\omega_{0}
$$

If $Q_{w t}$ is represented as per unit value (positive $Q_{w t}$ defined as WTs providing capacitive reactive power to the offshore ac network) where the power rating of the respective WT is used as the based power, same $k_{q}$ and $Q_{0}$ can be used for all the WTs to achieve equal reactive power sharing (based on their respective power rating).

\section{6) Start-up strategy}

Diode rectifier cannot supply the energy for offshore network during the start-up, thus additional power source is required. In [12], [13], umbilical ac cables are used to start-up the unidirectional DR-HVDC. In this study, umbilical ac cables are not considered and it is assumed that there are energy storage installed at some WTs to provide self-startup capability.

During the start-up, WT converters operate at ac voltage control mode to establish the ac voltage. In order to avoid active power circulation among WT converters, active power / ac voltage droop control is adopted, which is realized by setting the integrator coefficient $\left(k_{p i}\right)$ in the active power control (shown in Fig. 2) at 0.

\section{DISTRIBUTED PLL-BASED FREQUENCY CONTROL}

Due to the uncontrollability of the diode rectifier, the system needs to ensure that large numbers of WTs work autonomously to provide frequency control of the offshore system. To tackle this problem, a distributed PLL-based frequency control is proposed for each turbine, as illustrated in Fig. 2. In addition to the frequency controllability, the proposed control ensures plug-and-play capability providing automatic synchronization of the offline WTs and minimum impact during disconnection of some of the turbines with the offshore ac network. Such issues have not been considered previously [8], [9].

\section{A. Principle of distributed PLL-based frequency control}

In the existing voltage control for isolated converter based networks, the voltage amplitude of the network is regulated by the $d$-axis voltage reference $U_{F d r e f}$ while the $q$-axis reference $U_{F q r e f}$ is normally set at zero. On the other hand, the PLL takes $U_{F q}$ as the input and regulates the frequency output to ensure the $q$-axis voltage $U_{F q}$ to zero, as shown in Fig. 3. For example if the measured $U_{F q}$ is slightly larger than zero for a short time, the detected frequency of the voltage vector will increase, as shown in Fig. 4 and (7)

$$
\omega=k_{l p} U_{F q}+k_{l i} \int U_{F q} d t+\omega_{0}
$$

Since the frequency and phase angle measured by the PLL will also drive (synchronize) the output of the converter for the offshore ac network, the frequency of the offshore system will increase under such conditions. This indicates that the $q$-axis voltage reference $U_{\text {Fqref }}$ can be used to control the ac frequency and thus an additional PLL-based frequency loop is proposed to generate the desired $U_{\text {Fqref }}$, as shown in Fig. 2 and expressed as

$$
U_{\text {Fqref }}=k_{f}\left(\omega_{\text {ref }}-\omega\right)
$$

When $\omega<\omega_{\text {ref }}$ (i.e. $U_{\text {Fqref }}>0$ ), the PLL-based frequency control produces a positive $U_{\text {Fqref }}$ feeding to the ac voltage controller, as seen in Fig. 2. The voltage and current loops ensure the converter produce the required $U_{F q}$ according to its reference value produced by the frequency loop. Consequently the frequency measured by the PLL is increased (due to $U_{F q}>0$ ) until becoming identical to the reference $\left(\omega=\omega_{\text {ref }}\right)$. Similarly, when $\omega>\omega_{\text {ref }}$ (i.e. $U_{\text {Fqref }}<0$ ), the proposed frequency control produces a negative $U_{F q}$ so the frequency is reduced accordingly. Such frequency control can be implemented at each line-side converter of the WTs and is able to operate autonomously to contribute to the overall frequency regulation of the offshore ac network.

Fig. 5 shows the frequency regulation of the proposed PLLbased frequency control enabled at $0.4 \mathrm{~s}$ for a $5 \mathrm{MW}$ converter (parameters seen in Table I). For case 1, the initial frequency is higher than the reference frequency of $50 \mathrm{~Hz}$ whereas for case 
This paper is a post-print of a paper submitted to and accepted for publication in IEEE Transactions on Power Delivery and is subject to Institution of Electrical and Electronic Engineering Copyright. The copy of record is available at IEEE Xplore Digital Library.

2, it is lower than $50 \mathrm{~Hz}$. As can be seen, both frequencies quickly follow the reference after enabling the proposed frequency control at $0.4 \mathrm{~s}\left(k_{f}\right.$ steps from 0 to 0.01$)$.

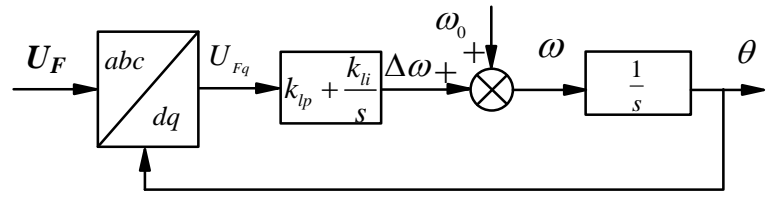

Fig. 3 Diagram of the PLL

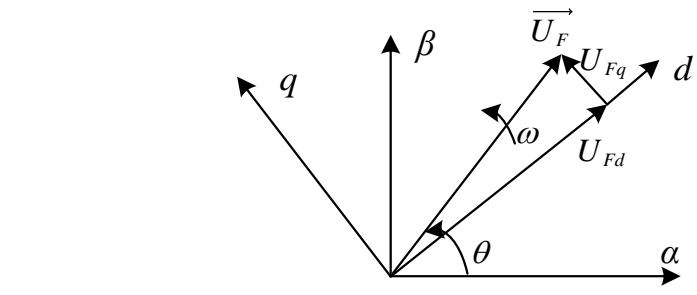

Fig. 4 Voltage vector in $d q$ reference frame

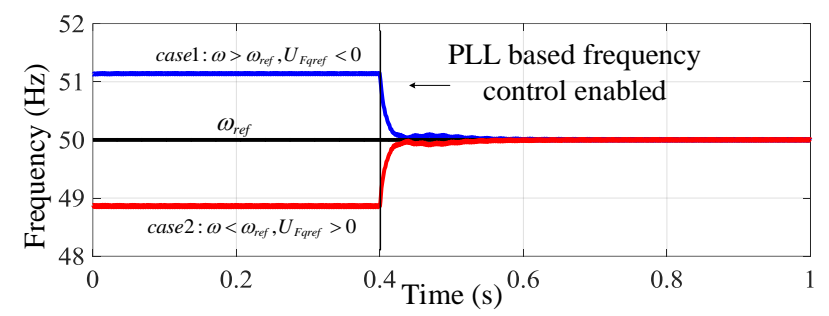

Fig. 5 Frequency regulation using the proposed PLL-based frequency control

\section{B. Stability analysis of PLL-based frequency control}

The frequency loop with the proposed control is analyzed in this subsection and the stability range of the frequency gain $k_{f}$ is derived.

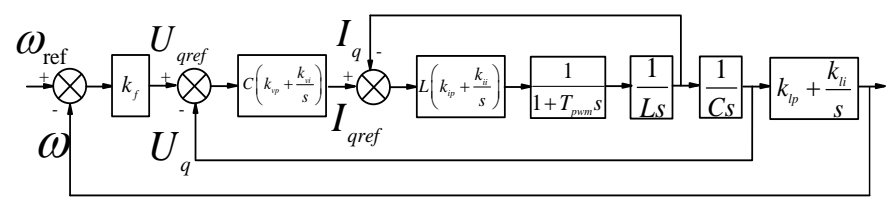

Fig. 6 Closed loop of PLL-based frequency control

The closed loop of the PLL-based frequency control, including the voltage, current loops and PLL, is represented in Fig. 6. The converter including the PWM modulator is approximated using a first order delay. The closed loop transfer function is thus expressed as

$$
H(s)=\frac{G(s)}{1+G(s)} .
$$

In (9), $G(s)$ is the open loop transfer function and is written as

$$
G(s)=\frac{k_{f}\left(a s^{3}+b s^{2}+c s+d\right)}{T_{p w m} s^{6}+s^{5}+e s^{4}+f s^{3}+g s^{2}+h s}
$$

where

$$
\begin{aligned}
& a=k_{i p} k_{v p} k_{l p} ; \\
& b=k_{i i} k_{v p} k_{l p}+k_{v i} k_{i p} k_{l p}+k_{l i} k_{i p} k_{v p} ; \\
& c=k_{i i} k_{v i} k_{l p}+k_{i i} k_{l i} k_{v p}+k_{v i} k_{l i} k_{i p} ; \\
& d=k_{i i} k_{v i} k_{l i} ; e=k_{i p} ; f=k_{i i}+k_{i p} k_{v p} ; \\
& g=k_{i i} k_{v p}+k_{v i} k_{i p} ; h=k_{i i} k_{v i} ;
\end{aligned}
$$

For the line-side converter of a 5MW WT converter with parameters listed in Table I, the PI parameters of the current loop, voltage loop, and PLL are $\left(k_{i p}=1256 \Omega, k_{i i}=98696 \Omega . / \mathrm{s}\right)$; $\left(k_{v p}=251 \Omega^{-1}, k_{v i}=15775 \Omega^{-1} \mathrm{~s}^{-1}\right)$; and $\left(k_{l p}=223.21 \mathrm{rad} . /(\mathrm{sv})\right.$, $\left.k_{l i}=7042.5 \mathrm{rad} . /\left(\mathrm{s}^{2} \mathrm{v}\right)\right)$ respectively. $L$ and $C$ are listed in Table I. $T_{p w m}$ is half of VSC switching period of $0.5 \mathrm{~ms}$. From (9)-(11), the corresponding root locus is shown in Fig. 7.

As illustrated in Fig. 7, the PLL-based frequency control is stable when $k_{f}<0.057$ in this case. Although the increase of $k_{f}$ leads to fast frequency control response, the damping is reduced.

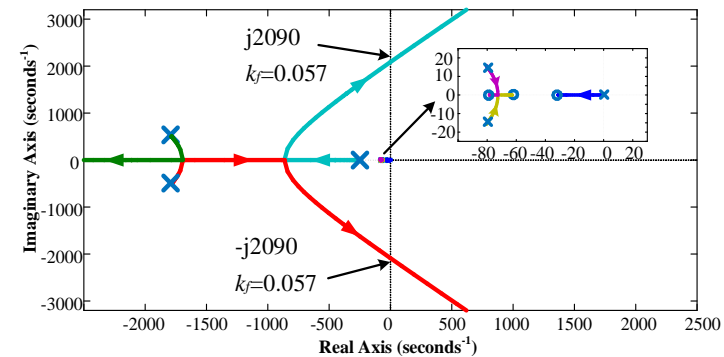

Fig. 7 Closed loop root-locus of PLL-based frequency control

\section{FAULT RIDE-THROUGH DURING ONSHORE AC FAULT}

\section{A. Onshore ac fault characteristics}

During an onshore ac fault, it is desirable that the offshore system and the DR-HVDC can remain operational, and continue transmitting active power from WTs and support the onshore ac grid. With the sudden drop of the ac voltage during a severe three-phase fault, the onshore MMC will operate in current limit mode and active power that can be transmitted will be significantly reduced. However, in the meantime the WTs and diode rectifier still try to transfer the generated power to the dc link, leading to active power unbalance in the DR-HVDC system. The surplus power will have to be stored in the dc cable and submodule capacitors of the onshore MMC station resulting in dc system overvoltage.

The amount of power that can be transmitted from the offshore wind farm after the onshore fault depends largely on the dc voltage of the HVDC system:

- If the dc voltage is controlled at a constant value during the onshore fault by the MMC station, the WT converters will continue delivering generated active power. The constant active power unbalance due to the reduced output power to the onshore ac system can result in excessive overvoltage in the MMC submodules and potentially lead to system disconnection. Fast communication may have to be used to reduce the offshore wind power generation to achieve active power re-balance.

$\circ \mathrm{dc}$ voltage increases during the onshore fault. WT converter active power control will push up the ac voltage until the maximum ac voltage limit is reached. Consequently, the offshore active power transmission is reduced and power re-balance between the offshore and onshore sides is achieved automatically without the use of communication. If the dc voltage can be increased quickly at the initial stage of the fault, active power re-balance can be achieved faster leading to reduced capacitor 
This paper is a post-print of a paper submitted to and accepted for publication in IEEE Transactions on Power Delivery and is subject to Institution of Electrical and Electronic Engineering Copyright. The copy of record is available at IEEE Xplore Digital Library.

overvoltage in the MMC submodules.

Two different methods (passive and active) for increasing the dc voltage during an onshore fault will be further described in the following sections.

\section{B. Passive MMC dc voltage control}

With the passive MMC dc voltage control, the dc voltage is directly linked to the submodule capacitor voltage in which the total number of inserted submodules in the upper and lower arms in each phase $(N)$ keeps constant, even during the onshore fault. The relationship between the increase of dc link voltage $\left(\Delta U_{d c}\right)$ and the submodule capacitor voltage increase $\left(\Delta U_{c}\right)$ can be expressed as

$$
\Delta U_{d c}=N \Delta U_{c}
$$

where submodule capacitor voltage increase is caused by the energy unbalance between offshore generation and onshore transmission. The increase of the dc link voltage, in turn, reduces the offshore transmitted active power until the active power is re-balanced between the offshore and onshore sides. For the DR-HVDC system with offshore ac voltage limit control, there is an intrinsic negative feedback loop after onshore fault that the unbalanced active power can always be automatically driven to 0 . The surplus energy at each WT is dealt with as part of WT fault ride through requirement.

\section{Active MMC dc voltage control}

As discussed before, faster dc voltage increase leads to faster active power re-balance. Thus, the energy absorbed by the MMC submodule capacitors can be reduced alleviating excessive overvoltage of the submodules. Based on this observation, an active MMC dc voltage control is proposed to automatically increase the dc voltage reference after the onshore fault, and the increase of the dc voltage and submodule voltage can be expressed as

$$
\Delta U_{d c}=k N \Delta U_{c}, \quad k>1
$$

A limiter on $\Delta U_{\mathrm{dc}}$ can be used in the proposed control to limit the HVDC link over-voltage in an acceptable range. After the dc link voltage hits the limit, the number of inserted submodules per phase starts to decrease with the increase of the submodule capacitor voltage. In this way, the HVDC link voltage is regulated at the pre-set maximum value to ensure safe operation of the HVDC link.

After the fault clearance, the onshore ac voltage restores and more active power can be exported from the MMC to the onshore grid. The DR-HVDC system and offshore wind generation can recover quickly.

The proposed control also works in normal operation (as $\Delta U_{\mathrm{c}}=0$ and $\left.\Delta U_{\mathrm{dc}}=0\right)$ and does not have any negative influence on the normal operation. The passive control shown in Section IV B is a specific case for the proposed active control where $k$ is set at unity, as depicted by (12) and (13). Hence, no fault detection, control mode switching or communication is required for the proposed control.

\section{Simulation Results}

The system similar to the one shown in Fig. 1 is simulated in
PSCAD/EMTDC environment to verify the proposed control of the DR-HVDC system with parameters listed in Table I. Detailed model is used for the diode rectifier, and equivalent MMC model from PSCAD library containing 256 submodules per arm is used for the onshore converter [18]-[20]. The wind farm model includes the followings: ten 5 MW WTs representing one WT string, an aggregate $150 \mathrm{MW}$ WT (equivalent to 3 WT strings), an aggregate $200 \mathrm{MW}$ WT (equivalent to a WT cluster with 4 strings) and an aggregate 600 MW WT (equivalent to 3 WT clusters). WTs' mechanical parts and generate-side converters are not modelled and the line-side converters are connected to constant dc voltage sources [8], [9], and use detailed switching models.

\begin{tabular}{|c|c|c|}
\hline \multicolumn{3}{|c|}{ PARAMETERS OF THE TESTED DR-HVDC SYSTEM } \\
\hline Components & Parameters & Values \\
\hline \multirow{2}{*}{ DR-HVDC link } & Power & $1000 \mathrm{MW}$ \\
\hline & dc voltage & $\pm 320 \mathrm{kV}$ \\
\hline \multirow{2}{*}{$\begin{array}{l}\text { 12-pulse } \\
\text { diode rectifier }\end{array}$} & $\begin{array}{l}\text { Transformer }(\mathrm{Y} / \mathrm{Y} / \Delta) \\
\text { Leakage inductance }\end{array}$ & $\begin{array}{l}66 / 261.8 / 261.8 \mathrm{kV}, \\
0.18 \mathrm{pu}\end{array}$ \\
\hline & Reactive power compensation & $0.3 \mathrm{pu}$ \\
\hline \multirow{5}{*}{ Onshore MMC } & Submodule capacitance & $8000 \mathrm{uF}$ \\
\hline & Submodule number per $\operatorname{arm} N$ & 256 \\
\hline & Submodule capacitor voltage & $2.5 \mathrm{kV}$ \\
\hline & Arm inductance & $0.067 \mathrm{pu}$ \\
\hline & Transformer $(\mathrm{Y} / \Delta)$ & $400 / 330 \mathrm{kV}$ \\
\hline \multirow{10}{*}{ WT converters } & Rating of individual WT & $5 \mathrm{MW}$ \\
\hline & Rating of a WT string & $5 \mathrm{MW} \times 10$ \\
\hline & Rating of a WT cluster & $200 \mathrm{MW}$ \\
\hline & $\begin{array}{l}\text { Transformer }(\mathrm{Y} / \Delta) \\
\text { Leakage inductance }\end{array}$ & $\begin{array}{l}0.69 / 66 \mathrm{kV} \\
0.08 \mathrm{pu}\end{array}$ \\
\hline & Filter capacitor $C$ & $0.1 \mathrm{pu}$ \\
\hline & Filter resistance & $0 \mathrm{pu}$ \\
\hline & Converter reactance $L$ & $0.15 \mathrm{pu}$ \\
\hline & Switching frequency & $2 \mathrm{kHz}$ \\
\hline & $\begin{array}{l}\text { Ac cable length between two } \\
5 \mathrm{MW} \text { WTs }\end{array}$ & $0.5 \mathrm{~km}$ \\
\hline & $\begin{array}{l}\text { Ac cable length (for each } \\
\text { aggregate converter) }\end{array}$ & $\begin{array}{l}5 \mathrm{~km}, 10 \mathrm{~km}, \\
20 \mathrm{~km}\end{array}$ \\
\hline
\end{tabular}

$$
\text { TABLE I }
$$

\section{A. Start-up and synchronization}

The performance of the proposed PLL-based control is verified first during start-up, with the assumption that the WT dc link initial energy is provided by WT energy storage. The time line of the simulation is listed in Table II.

At the beginning, the first 5 MW WT1 (seen in Fig. 1) is connected with its WT string, while the DR-HVDC dc link voltage is established by the onshore MMC. During 0-0.5 s, the voltage and frequency control of WT1 increases its output ac voltage $\left(U_{F}\right)$ and the offshore voltage ( $\left.U_{\text {off }}\right)$ to 0.86 pu with ac frequency at $50 \mathrm{~Hz}$, as shown in Figs. 8 (a), (h) and (g). At $1 \mathrm{~s}$, breaker BRK2 is closed to connect WT2 to the WT string, with the WT2 filter and transformer being energized.

At $1.2 \mathrm{~s}$, the proposed PLL-based control enables WT2 to synchronize automatically with the WT string. As seen from Figs. 8 (c) and (d), each WT active power output is around 0 (only needs compensate the power loss of the cables) while reactive power is well shared between these two WTs $(-0.33$ MVAr each). During 2-9.2 s, WT3--WT10 are enabled and synchronized with the WT string sequentially after closing each ac breaker. As seen in Fig. 8 (b), no overcurrent is observed 
This paper is a post-print of a paper submitted to and accepted for publication in IEEE Transactions on Power Delivery and is subject to Institution of Electrical and Electronic Engineering Copyright. The copy of record is available at IEEE Xplore Digital Library.

during the WT connection and synchronization.

At $10 \mathrm{~s}$, the breaker of the aggregate $150 \mathrm{MW}$ WT (equivalent to 3 WT strings) is closed and the corresponding WT filter and transformer are energized. At $10.2 \mathrm{~s}$, the aggregate $150 \mathrm{MW}$ is enabled and synchronized with the offshore network. At $11 \mathrm{~s}$, the breaker of the aggregate $200 \mathrm{MW}$ WT (equivalent to a WT cluster) is closed to energize the corresponding WT filter and transformer. At $11.2 \mathrm{~s}$, the aggregate $200 \mathrm{MW}$ WT is enabled and synchronized with the offshore network. As can be seen in Figs.8 (a), (b), (g) and (h), the synchronization is very smooth even with such large lumped converter and the offshore ac voltage and frequency are well controlled.

TABLE II

SEQUENCE OF START-UP AND SYNCHRONIZATION

\begin{tabular}{l|l}
\hline Time & Events \\
\hline $0 \mathrm{~s}$ & Breaker BRK1 (seen in Fig. 1) is closed \\
\hline $0-0.5 \mathrm{~s}$ & $\begin{array}{l}\text { WT1 establishes ac voltage and frequency, operating in } \\
\text { islanded mode }\end{array}$ \\
\hline $1.0 \mathrm{~s}$ & $\begin{array}{l}\text { Breaker BRK2 closed, filter and transformer of WT2 } \\
\text { energized }\end{array}$ \\
\hline $1.2 \mathrm{~s}$ & WT2 enabled, operating in islanded mode \\
\hline$\ldots$ & $\ldots$ \\
\hline $9 \mathrm{~s}$ & $\begin{array}{l}\text { Breaker BRK10 closed, filter and transformer of WT10 } \\
\text { energized }\end{array}$ \\
\hline $9.2 \mathrm{~s}$ & WT10 enabled, operating in islanded mode \\
\hline $10 \mathrm{~s}$ & $\begin{array}{l}\text { Breaker of aggregate 150 MW WT closed, filter and } \\
\text { transformer of WT energized }\end{array}$ \\
\hline $10.2 \mathrm{~s}$ & $\begin{array}{l}\text { Aggregate 150 MW WT enabled, operating in islanded } \\
\text { mode }\end{array}$ \\
\hline $11 \mathrm{~s}$ & $\begin{array}{l}\text { Breaker of aggregate 200 MW WT closed, filter and } \\
\text { transformer of WT energized }\end{array}$ \\
\hline $11.2 \mathrm{~s}$ & $\begin{array}{l}\text { Aggregate 200 MW WT enabled, operating in islanded } \\
\text { mode }\end{array}$ \\
\hline $12 \mathrm{~s}$ & $\begin{array}{l}\text { Diode rectifier and transformer energized and connected, } \\
150 \text { MVAr filter energized and connected }\end{array}$ \\
\hline $12.5-12.8 \mathrm{~s}$ & WT1 starts power production \\
\hline $13-13.3 \mathrm{~s}$ & WT2 starts power production \\
\hline $13.5-13.8 \mathrm{~s}$ & WT3 starts power production \\
\hline $14-14.3 \mathrm{~s}$ & WT4--WT10 starts power production \\
\hline $14.5-14.8 \mathrm{~s}$ & Aggregate 150 MW WT starts power production \\
\hline $15-15.3 \mathrm{~s}$ & Aggregate 200 MW WT starts power production \\
\hline $15.5 \mathrm{~s}$ & Breaker of aggregate 600 MW WT closed \\
\hline $16-16.3 \mathrm{~s}$ & $\begin{array}{l}\text { Aggregate } 600 \mathrm{MW} \text { WT enabled and increase power } \\
\text { production to 300 MW }\end{array}$ \\
\hline $16.5 \mathrm{~s}$ & A 150 MVAr diode rectifier filter added \\
\hline $17-17.3 \mathrm{~s}$ & $\begin{array}{l}\text { Aggregate } 600 \mathrm{MW} \text { WT increases power production from } \\
300 \text { MW to 600 MW }\end{array}$ \\
\hline
\end{tabular}

At $12 \mathrm{~s}$, the breaker of the diode rectifier is closed. Thus, the diode rectifier, transformer and the $150 \mathrm{MVAr}$ filter are energized. From $12.5 \mathrm{~s}$ to $12.8 \mathrm{~s}$, first WT starts power production, ramping active power from 0 to its rated value of 5 MW as seen in Fig. 8 (c). After the conduction of the diode rectifier, the offshore ac voltage increases to $0.9 \mathrm{pu}$ in order to transmit active power. From $13 \mathrm{~s}$ to $13.3 \mathrm{~s}$ and $13.5 \mathrm{~s}$ to $13.8 \mathrm{~s}$, WT2 and WT3 increase active power production to its rated value respectively. From 14-14.3 s, WT4-WT10 increase active power production to rated value at the same time. After $14.3 \mathrm{~s}$, all the ten WTs in this string operate at the rated active power,

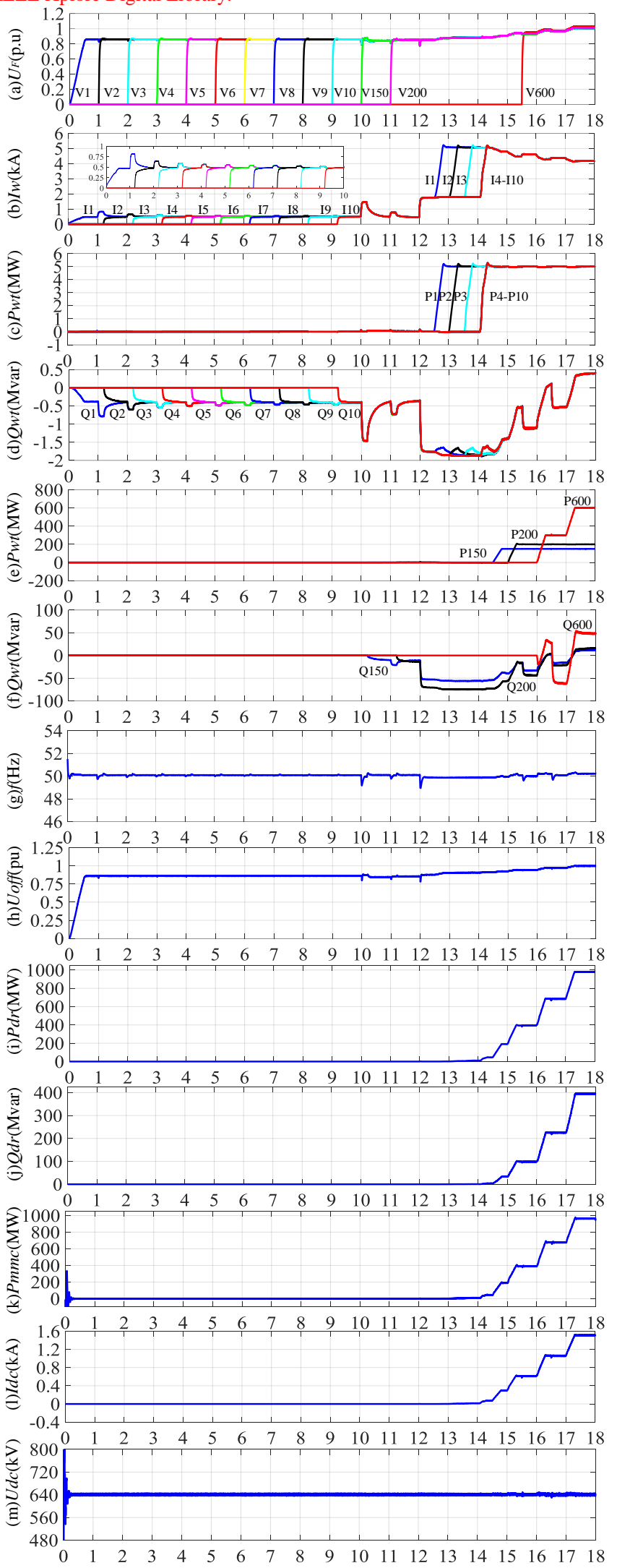

Fig. 8 Performance of start-up and synchronization: (a) WT voltage (RMS); (b) WT current (RMS); (c) WT active power; (d) WT reactive power; (e) aggregate WT power;(f) aggregate WT reactive power; (g) offshore frequency; (h) offshore voltage; (i) diode rectifier transmitted active power; (j) diode rectifier reactive power consumption; (k) onshore transmitted active power; (l) dc current; (m) dc voltage 
This paper is a post-print of a paper submitted to and accepted for publication in IEEE Transactions on Power Delivery and is subject to Institution of Electrical and Electronic Engineering Copyright. The copy of record is available at IEEE Xplore Digital Library.

with offshore frequency being regulated at around $50 \mathrm{~Hz}$ and reactive power well shared among WTs (-1.8 MVAr each).

During 14.5-14.8 s, the generated active power from the aggregate $150 \mathrm{MW}$ WT increases from 0 to $150 \mathrm{MW}$, as shown in Fig. 8 (e). Meanwhile, the diode rectifier reactive power consumption grows to $33 \mathrm{MVAr}$, as shown in Fig. 8 (j). During $15-15.3 \mathrm{~s}$, the generated active power from the aggregate 200 MW WT increases from 0 to $200 \mathrm{MW}$ with the diode rectifier reactive power consumption of 97 MVAr. As a result, the reactive power absorbed by the WTs decreases accordingly to achieve the offshore network reactive power balance, as shown in Figs. 8 (d) and (f). When these WTs operate at the full rated power (at $\mathrm{t}=15.3 \mathrm{~s}$ in Fig. 8), the total transmitted active power is $400 \mathrm{MW}$, as shown in Fig.8 (i) and the offshore voltage $U_{\text {off }}$ is increased to $0.94 \mathrm{pu}$ with frequency largely remaining at 50 $\mathrm{Hz}$.

At $15.5 \mathrm{~s}$, the breaker of the aggregate $600 \mathrm{MW}$ WT (equivalent to $3 \mathrm{WT}$ clusters) is closed and the corresponding WT filter and transformer are energized. During 16-16.3 s, its output power is increased from 0 to $300 \mathrm{MW}$. Meanwhile, all the wind turbines start to export reactive power to compensate the increased reactive power consumption by the diode rectifier (227 MVAr). At 16 s, a 150 MVAr filter is added. During 17$17.3 \mathrm{~s}$, the aggregate $600 \mathrm{MW}$ WT further increases active power from $300 \mathrm{MW}$ to $600 \mathrm{MW}$.

From $17.3 \mathrm{~s}$, the DR-HVDC system operates at the rated active power with dc current and onshore active power at rated value, as shown in Figs. 8 (1) and (k). The offshore voltage $U_{\text {off }}$ is now $1 \mathrm{pu}$, with the total harmonic distortion (THD) at around $1 \%$ and frequency controlled at around $50 \mathrm{~Hz} .400 \mathrm{MVAr}$ reactive power is consumed by the diode rectifier. As can be seen from Figs. 8 (d) and (f), under steady state, the reactive power are shared equally (in per unit terms with respect to their respective rated power). During the whole start-up and WT connection process, the dc voltage is well controlled by the onshore MMC, as shown in Fig. 8 (m). The THD of the offshore voltage $U_{\text {off }}$ is lower than $1.5 \%$ throughout the wind power range of 0 to $1 \mathrm{pu}$, as shown in Table III.

As seen from Fig. 8, the offshore network shows an excellent behavior during the start-up and synchronization. Offline WT converters synchronize seamlessly with the offshore network during the connection process, and the overall offshore network frequency is also well controlled by the distributed WT converters.

TABLE III THD OF OFFSHORE VOLTAGE

\begin{tabular}{l|l|l|l|l|l|l}
\hline Power $(\mathrm{pu})$ & 0 & 0.1 & 0.2 & 0.3 & 0.4 & 0.5 \\
\hline THD & $0.55 \%$ & $0.68 \%$ & $0.7 \%$ & $0.8 \%$ & $0.9 \%$ & $1.37 \%$ \\
\hline Power $(\mathrm{pu})$ & 0.6 & 0.7 & 0.8 & 0.9 & 1.0 & \\
\hline THD & $1.06 \%$ & $1.1 \%$ & $0.84 \%$ & $0.96 \%$ & $1.1 \%$ & \\
\hline
\end{tabular}

\section{B. Onshore fault ride-through operation}

The performance of the active dc voltage control during a solid onshore fault is compared to that of the passive dc voltage control method and the simulation results are shown in Fig. 9.

During normal operation, both control methods operate satisfactorily. At $0.05 \mathrm{~s}$, a solid three-phase onshore fault occurs at the transformer primary side and the onshore ac voltage rapidly decreases to 0 , as shown in Fig. 9 (a). The onshore transmitted active power quickly reduces to 0 as shown in Fig. 9 (h), while the WT and diode rectifier still try to transmit the
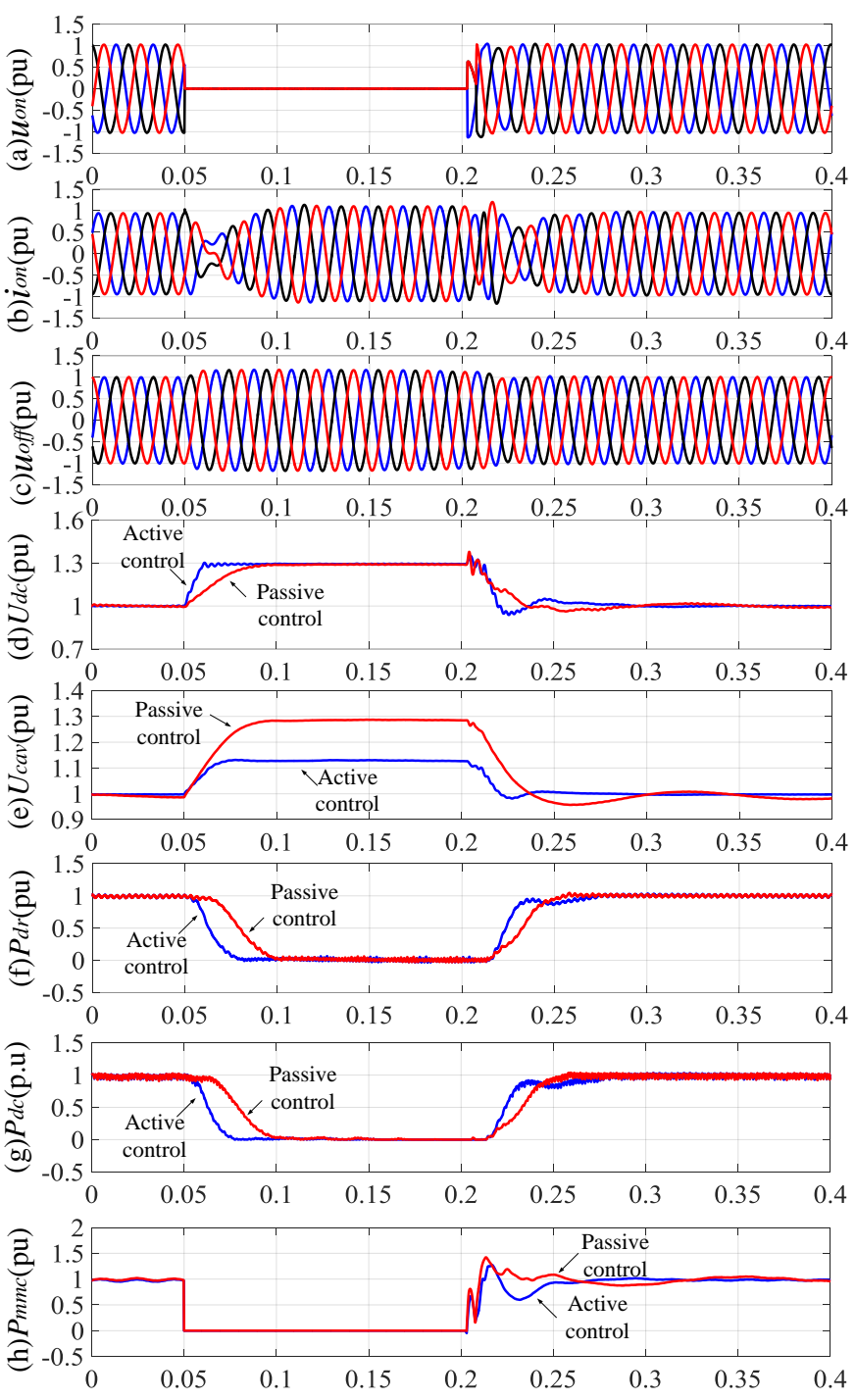

Fig. 9 Performance of the DR-HVDC system during onshore solid fault: (a) onshore ac voltage; (b) onshore ac current; (c) offshore ac voltage; (d) dc voltage; (e) average MMC submodule capacitor voltage of six arms; (f) total WT transmitted active power; (g) dc power; (h) onshore transmitted active power

generated active power, as shown in Figs. 9 (f) and (g). During the fault, the active current of the MMC is reduced using a voltage dependent current order limit (VDCOL) while its reactive current is increased [21]. This unbalanced active power leads to the charge of MMC submodule capacitors and consequently their voltages (shown as the average value of all the submodules) increase as shown in Fig. 9 (e).

With the conventional passive dc voltage control method, both the average submodule voltage of the 6 arms and the dc voltage increase from $1.0 \mathrm{pu}$ to $1.29 \mathrm{pu}$ in $0.04 \mathrm{~s}$, as shown in Figs. 9 (d) and (e). The increase of the dc voltage reduces the power output from the WT and transmitted to dc by the offshore diode rectifier as can be seen in Figs. 9 (f) and (g). When the dc 
This paper is a post-print of a paper submitted to and accepted for publication in IEEE Transactions on Power Delivery and is subject to Institution of Electrical and Electronic Engineering Copyright. The copy of record is available at IEEE Xplore Digital Library.

voltage reaches $1.29 \mathrm{pu}$, the offshore ac voltage is limited by the WT converters (set at $1.1 \mathrm{pu}$ ) and thus no active power can be generated and transmitted to the dc. The excess power in individual WT needs to be dealt with as part of WT fault ride through strategy, e.g. using dc damping resistors so is not investigated here.

Using the proposed active dc voltage control method, the dc voltage increases to $1.29 \mathrm{pu}$ within the first $0.01 \mathrm{~s}$ and the offshore ac voltage is quickly limited by the voltage limit control at 1.1 p.u, as shown in Fig. 9 (c). The faster dc voltage increase yields faster reduction of wind power generation and the energy absorbed by the MMC submodules is decreased. As a result, the submodule overvoltage is only $1.12 \mathrm{pu}$ with the proposed active control compared to 1.29 pu with conventional passive control, as shown in Fig. 9 (e). At $0.2 \mathrm{~s}$, the fault is cleared and the onshore ac voltage recovers, leading to the increase of onshore transmitted active power. As seen from Figs. 9 (f), the wind power generation is also quickly restored.
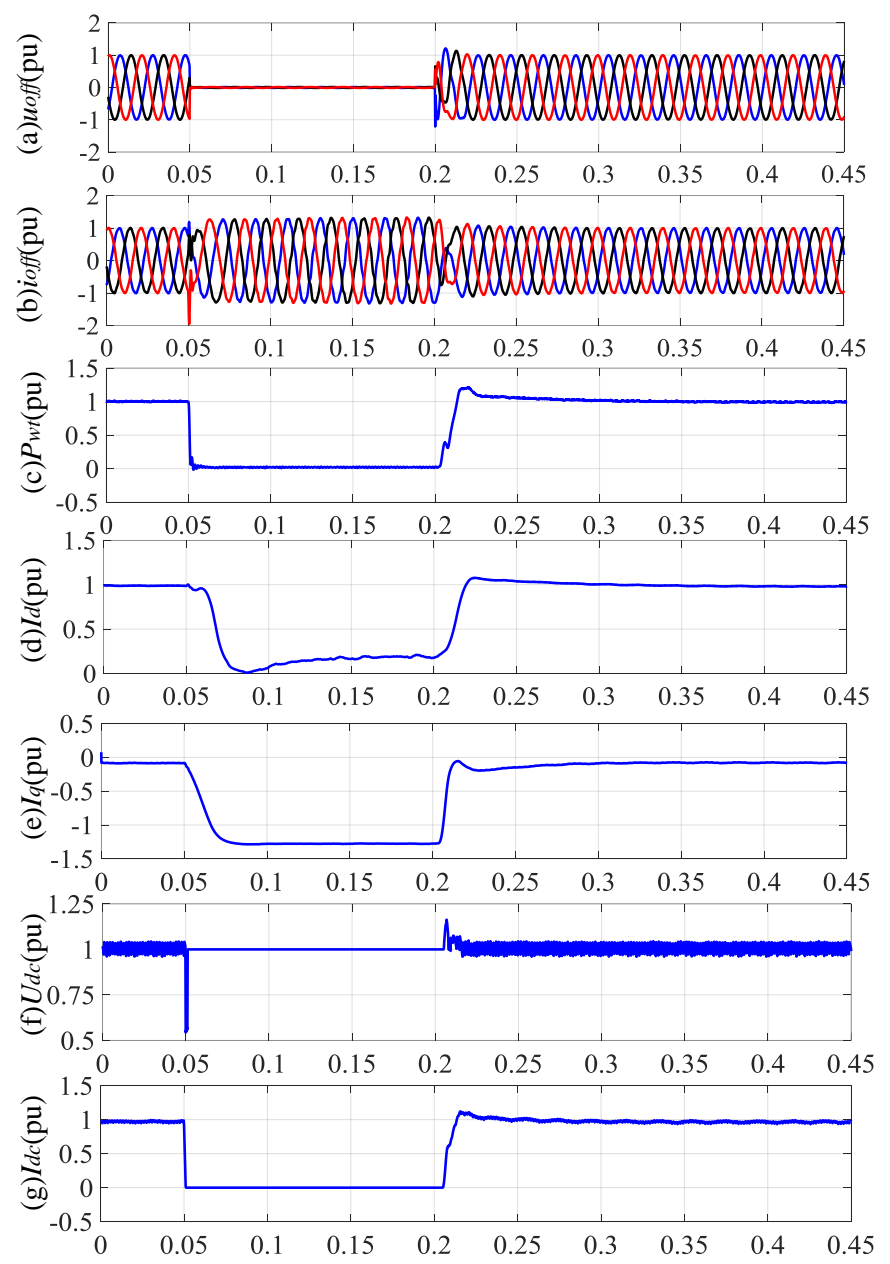

Fig. 10 Performance of the DR-HVDC system during offshore solid fault: (a) offshore ac voltage; (b) offshore ac current; (c) aggregate $150 \mathrm{MW}$ WT transmitted active power; (d) aggregate $150 \mathrm{MW}$ WT active current; (e) aggregate $150 \mathrm{MW}$ WT reactive current; (f) dc voltage of DR; (g) dc current.

\section{Offshore fault ride-through operation}

The performance of wind turbines connected with DRHVDC system during offshore fault is shown in Fig. 10 where a solid three-phase offshore fault occurs at the primary side of the diode rectifier transformer at $0.05 \mathrm{~s}$.

As shown in Fig.10 (a), the offshore AC voltage rapidly decreases to 0 after the fault. The drop of the ac offshore voltage leads to the reduction of active power transmission through the DR-HVDC link and the dc current quickly reduces to 0 , as shown Fig.10 (g). The active power from the wind turbine converters also decreases immediately to 0 as indicated in Fig. 10 (c) for the aggregate 150MW WT. However, the dc voltage of the DR-HVDC system is still controlled at $1 \mathrm{pu}$ by the onshore MMC, as shown in Fig. 10 (f). Meanwhile, the WT reactive current increases from -0.09 pu to -1.28 pu (capacitive) in order to achieve the reactive power re-balance after the offshore fault, as shown in Fig. 10 (e). As the reactive current is set as priority, the active current decreases from 1 pu to 0.2 pu to avoid overcurrent, as can be seen in Fig. 10 (d). Fig. 10 (b) shows the fault current is well controlled at around $1.3 \mathrm{pu}$ which is the maximum current set by the WT controller assuming $30 \%$ overcurrent capability.

At $0.2 \mathrm{~s}$, the offshore fault is cleared and the offshore ac voltage recovers, leading to the recovery of the reactive current from $-1.28 \mathrm{pu}$ to $-0.09 \mathrm{pu}$, and the active current restores to nominal value of 1 pu. As seen from the Fig. 10 (c) and (g), the wind power generation is quickly restored.

\section{CONCLUSION}

A distributed control of WT line-side converter for offshore wind farms connected by diode rectifier based HVDC system is proposed in this paper. The proposed method uses an additional PLL-based frequency loop to set the reference of the q-axis voltage component for frequency regulation. With the proposed control, each WT converter works autonomously to contribute to the overall offshore frequency regulation, and provides WTs with plug-and-play capability when offline WTs are synchronized to the offshore network. To ride-through an onshore fault, an active dc voltage control method is proposed for the onshore HVDC MMC converter. By inserting additional submodules to temporarily increase the dc link voltage, the power transmission from offshore wind farm through the diode rectifier can be quickly reduced thus to achieve faster active power re-balance between the offshore and onshore side and the MMC submodule capacitor overvoltage is thus alleviated due to the reduced surplus energy. Simulation results verify the proposed control strategy of DR-HVDC connected WTs during start-up, synchronization and under onshore and offshore fault condition.

\section{REFERENCE}

[1] S. M. Muyeen, R. Takahashi, and J. Tamura, "Operation and Control of HVDC-Connected Offshore Wind Farm," IEEE Trans. Sustain. Energy., vol. 1, pp. 30-37, 2010.

[2] X. Chen, H. Sun, J. Wen, W. J. Lee, X. Yuan, N. Li, et al., "Integrating Wind Farm to the Grid Using Hybrid Multiterminal HVDC Technology," IEEE Trans. Ind. Appl., vol. 47, pp. 965-972, 2011.

[3] O. Gomis-Bellmunt, A. Junyent-Ferre, A. Sumper, and J. Bergas-Jane, "Control of a Wind Farm Based on Synchronous Generators With a Central HVDC-VSC Converter," IEEE Trans. Power Syst., vol. 26, pp. 1632-1640, 2011. 
This paper is a post-print of a paper submitted to and accepted for publication in IEEE Transactions on Power Delivery and is subject to Institution of Electrical and Electronic Engineering Copyright. The copy of record is available at IEEE Xplore Digital Library.

[4] F. Deng and Z. Chen, "Design of Protective Inductors for HVDC Transmission Line Within DC Grid Offshore Wind Farms," IEEE Trans. Power Del., vol. 28, pp. 75-83, 2013.

[5] P. Mitra, L. Zhang, and L. Harnefors, "Offshore Wind Integration to a Weak Grid by VSC-HVDC Links Using Power-Synchronization Control: A Case Study," IEEE Trans. Power Del., vol. 29, pp. 453-461, 2014.

[6] J. Liang, T. Jing, O. Gomis-Bellmunt, J. Ekanayake, and N. Jenkins, "Operation and Control of Multiterminal HVDC Transmission for Offshore Wind Farms," IEEE Trans. Power Del., vol. 26, pp. 2596-2604, 2011.

[7] R. E. Torres-Olguin, M. Molinas, and T. Undeland, "Offshore Wind Farm Grid Integration by VSC Technology With LCC-Based HVDC Transmission," IEEE Trans. Sustain. Energy., vol. 3, pp. 899-907, 2012.

[8] R. Blasco-Gimenez, S. Ano-Villalba, J. Rodriguez-D'Derlee, et al., "Distributed Voltage and Frequency Control of Offshore Wind Farms Connected With a Diode-Based HVdc Link," IEEE Trans. Power Electron., vol. 25, pp. 3095-3105, 2010.

[9] R. Blasco-Gimenez, S. Ano-Villalba, J. Rodriguez-D'Derlee, et al., "Diode-Based HVdc Link for the Connection of Large Offshore Wind Farms," IEEE Trans. Energy Convers., vol. 26, pp. 615-626, 2011.

[10] S. Bernal-Perez, S. Ano-Villalba, R. Blasco-Gimenez, and J. RodriguezD'Derlee, "Efficiency and Fault Ride-Through Performance of a DiodeRectifier- and VSC-Inverter-Based HVDC Link for Offshore Wind Farms," IEEE Trans. Ind. Electron., vol. 60, pp. 2401-2409, 2013.

[11] R. Blasco-Gimenez, N. Aparicio, S. Ano-Villalba, and S. Bernal-Perez, "LCC-HVDC Connection of Offshore Wind Farms With Reduced Filter Banks," IEEE Trans. Ind. Electron., vol. 60, pp. 2372-2380, 2013.

[12] P. Menke, R. Zurowski, T. Christ, S. Seman, G. Giering, T. Hammer, et al., "2nd Generation DC Grid Access for Large Scale Offshore Wind Farms," in Proceedings of the 14th Wind Integration Workshop,Brussels, Belgium, 20th-22nd Oct. , 2015.

[13] S. Seman, R. Zurowski, and C. Taratoris, "Interconnection of advanced Type 4 WTGs with Diode Rectifier based HVDC solution and weak AC grids," in Proceedings of the 14th Wind Integration Workshop,Brussels, Belgium, 20th-22nd Oct. , 2015.

[14] C. Prignitz, H. G. Eckel, S. Achenbach, F. Augsburger, and A. Schön, "FixReF: A control strategy for offshore wind farms with different WTtypes and diode rectifier HVDC transmission," in 2016 IEEE 7th International Symposium on Power Electronics for Distributed Generation Systems (PEDG), 2016, pp. 1-7.

[15] T. H. Nguyen, D. C. Lee, and C. K. Kim, "A Series-Connected Topology of a Diode Rectifier and a Voltage-Source Converter for an HVDC Transmission System," IEEE Trans. Power Electron., vol. 29, pp. 1579$1584,2014$.

[16] V. Kaura and V. Blasko, "Operation of a phase locked loop system under distorted utility conditions," IEEE Trans. Ind. Appl., vol. 33, pp. 58-63, 1997.

[17] J. Rocabert, A. Luna, F. Blaabjerg, and P. Rodríguez, "Control of Power Converters in AC Microgrids," IEEE Trans. Power Electron., vol. 27, pp. 4734-4749, 2012.

[18] U. N. Gnanarathna, A. M. Gole, and R. P. Jayasinghe, "Efficient Modeling of Modular Multilevel HVDC Converters (MMC) on Electromagnetic Transient Simulation Programs," IEEE Trans. Power Del., vol. 26, pp. 316324, 2011.

[19] A. Beddard, M. Barnes, and R. Preece, "Comparison of Detailed Modeling Techniques for MMC Employed on VSC-HVDC Schemes," IEEE Trans. Power Del., vol. 30, pp. 579-589, 2015.

[20] J. Xu, C. Zhao, W. Liu, and C. Guo, "Accelerated Model of Modular Multilevel Converters in PSCAD/EMTDC," IEEE Trans. Power Del., vol. 28, pp. 129-136, 2013.

[21] L. Xu, L. Yao, and C. Sasse, "Grid Integration of Large DFIG-Based Wind Farms Using VSC Transmission," IEEE Trans. Power Syst., vol. 22, pp. 976-984, 2007.

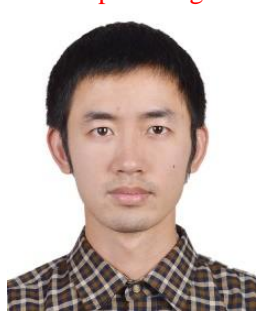

Lujie Yu received the B.S. and M.S. degree from North China Electric Power University (NCEPU), Beijing, China, in 2012 and 2015. He is currently pursuing the Ph.D degree in Electronic \& Electrical Engineering, University of Strathclyde, Glasgow, UK.

His research interests include HVDC transmision system and wind power integration.

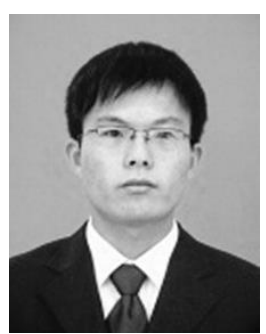

Rui Li received the M.S. and Ph.D degrees in electrical engineering from Harbin Institute of Technology, Harbin, China, in 2008 and 2013, respectively. Since 2013, he has been working as a research associate with University of Strathclyde in Glasgow, UK.

His research interests include HVDC transmision system, grid integration of renewable power, power electronic converters, and energy conversion.

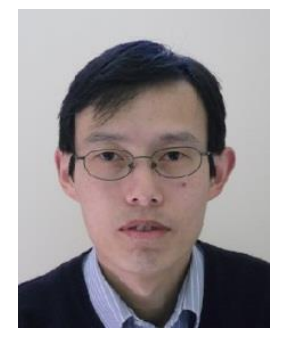

Lie Xu (M'03-SM'06) received the B.Sc. degree in Mechatronics from Zhejiang University, Hangzhou, China, in 1993, and the Ph.D. degree in Electrical Engineering from the University of Sheffield, Sheffield, UK, in 2000.

He is currently with the Department of Electronic \& Electrical Engineering, University of Strathclyde, Glasgow, UK. He previously worked in Queen's University of Belfast and ALSTOM T\&D, Stafford, UK. His research interests include power electronics, wind energy generation and grid integration, and application of power electronics to power systems. 